\title{
Spatial variability of microbial communities of the coralline demosponge Astrosclera willeyana across the Indo-Pacific
}

\author{
Klementyna Karlińska-Batres ${ }^{1}$, Gert Wörheide ${ }^{1,2, *}$ \\ ${ }^{1}$ Department of Earth and Environmental Sciences, Palaeontology and Geobiology \& GeoBio-Center, \\ Ludwig-Maximilians-Universität München, Richard-Wagner-Str. 10, 80333 München, Germany \\ ${ }^{2}$ Bayerische Staatssammlung für Paläontologie und Geologie, Richard-Wagner-Str. 10, 80333 München, Germany
}

\begin{abstract}
The coralline sponge Astrosclera willeyana, considered to be a living representative of the reef-building stromatoporoids of the Mesozoic and Paleozoic, is the most common coralline sponge found throughout Indo-Pacific coral reefs. Here, we used molecular methods to examine the microbiota of $A$. willeyana over nearly its whole geographic range, from the Red Sea to the central Pacific. Denaturing gradient gel electrophoresis analyses of 42 Astrosclera specimens revealed a high microbial diversity and a complex composition in all of the investigated samples. Clearly distinct banding patterns indicated closer associations of the microbiota according to their geographic origin. Moreover, we provide the first insights into the hitherto undetermined diversity and composition of microbial communities associated with coralline sponges from the Red Sea. Random sequencing of a $16 \mathrm{~S}$ rRNA clone library constructed from a single specimen of $A$. willeyana from the northern Red Sea exposed a very complex microbial consortium, with the most abundant being Chloroflexi, followed by Gammaproteobacteria and Deltaproteobacteria. Further members of the community belonged to Actinobacteria, Alphaproteobacteria, Acidobacteria, Deferribacteria, Nitrospirae, Gemmatimonadetes, Spirochaetes as well as 1 uncertain bacterial group. A comparison with a $16 \mathrm{~S}$ rRNA clone library obtained previously from $A$. willeyana from the Great Barrier Reef revealed both similarities and substantial differences in the composition of the microbiota. This study provides novel information on microbiota in coralline sponges, a diversity that has not been sufficiently investigated. Furthermore, it implies that the differences in symbiotic community composition may be an additional indicator of previously postulated cryptic host species.
\end{abstract}

KEY WORDS: Microbial community $\cdot$ Sponge $\cdot$ Cryptic species $\cdot$ Red Sea

\section{INTRODUCTION}

Marine sponges harbor abundant and diverse microbial communities (Taylor et al. 2007, Webster \& Taylor 2012); those of the most ancient symbiotic associations between microorganisms and metazoans are estimated to have been in existence for 600 million yr (Wilkinson 1984). Microbial communities may contribute up to $70 \%$ of the sponges' biomass (Wörheide 1998) and impact host metabolism, health, and evolution (see Taylor et al. 2007, Webster \& Taylor 2012 for a review). Recent comprehensive phyloge-

\footnotetext{
${ }^{*}$ Corresponding author: woerheide@lmu.de
}

netic analyses on 7546 sponge-derived $16 \mathrm{~S}$ and $18 \mathrm{~S}$ rRNA sequences confirmed the existence of spongespecific microbes, and in total $27 \%$ of the sequences in that study fell into monophyletic, sponge-specific sequence clusters (Simister et al. 2012). However, next-generation sequencing analysis revealed that putatively sponge-specific bacteria also occur in other marine environments and are probably capable of surviving outside the host, although generally at extremely low abundances (Webster et al. 2010, Taylor et al. 2013). Microbial communities in sponges are regarded as highly specific to the host species and

() The authors 2015. Open Access under Creative Commons by Attribution Licence. Use, distribution and reproduction are unrestricted. Authors and original publication must be credited. 
generally stable across time and space (Taylor et al. 2007). In a recent pyrosequencing analysis of 32 marine sponge species from 8 locations worldwide, Schmitt et al. (2012) hypothesized that different sponges share a very small 'core community,' and that they host mainly species-specific communities. These results suggest that broader investigations of microbial diversity in different sponge species may contribute to a clarification of sponge-specific microbiota, which may play a key role in the evolution of this putatively ancient symbiosis and in sponge response to climate change and environmental stress (Webster et al. 2011, 2013, Webster \& Taylor 2012).

Astrosclera willeyana belongs to a group of coralline sponges which build a solid secondary calcareous skeleton (Reitner 1992, Chombard et al. 1997) in addition to a primary, often spicular, one. Coralline sponges (also called sclerosponges) contributed to the construction of reefs, where they dominated in the late Paleozoic and Mesozoic (Vacelet 1985). Regarded as a 'living fossil,' A. willeyana occurs in cryptic and light-reduced environments (e.g. reef caves; Reitner et al. 1996), from the northern Red Sea to Tahiti (Wörheide 1998), and is the most common coralline sponge throughout the Indo-Pacific coral reefs (Reitner et al. 1996). Vacelet (1981) was the first to observe that different regional populations of $A$. willeyana vary in spicule morphology, which is used as a criterion for taxonomic identification of the sponges. Based on a detailed morphological study of A. willeyana spicules distinguishing several regional populations (Wörheide 1998), and based on molecular investigations of nuclear internal transcribed spacer (ITS) rDNA, Wörheide et al. (2002a) proposed the presence of at least 3 distinct cryptic species. However, this hypothesis was not consistent with the results of a subsequent mitochondrial marker analysis - probably due to very low mtDNA substitution rates in this taxon (Wörheide 2006).

Wörheide (1998) was the first to report large microbial communities in the living tissue of $A$. willeyana from the Indo-Pacific and noted that bacteria may make up more than $70 \%$ of the total biomass of some parts of the sponge's body, although other parts of the sponge's tissues lack bacteria almost entirely (Wörheide 1998). Recently, we were the first to use molecular methods to explore the microbial diversity of coralline sponges (Karlińska-Batres \& Wörheide 2013a), and we also provided the first insight into the composition of the symbiotic community of A. willeyana from the Great Barrier Reef (GBR), Australia (Karlińska-Batres \& Wörheide 2013b). Denaturing gradient gel electrophoresis (DGGE) revealed a clear split in the microbiota of $A$. willeyana specimens from the southern and northern parts of the GBR, thus further corroboration was provided for the existence of $A$. willeyana cryptic species (KarlińskaBatres \& Wörheide 2013b). An investigation of the symbiotic communities of $A$. willeyana from other geographical locations will not only offer insight into the under-investigated microbial diversity in coralline sponges, but might also provide additional data to test the presence of cryptic species in Astrosclera.

Hence, we aimed to explore the differences in the microbial communities of $A$. willeyana over a wide geographic range, from the Red Sea to the central Pacific, and to test whether distinct microbiota correlate with the distribution of putative Astrosclera cryptic species. Therefore, we created a clone library from a microbial community of $A$. willeyana from the popular 'Canyon' dive site in the Gulf of Aqaba (Dahab, Red Sea) to compare it with a previously assessed clone library obtained from A. willeyana from Yonge Reef, GBR. Furthermore, we performed DGGE analysis to investigate any resemblance between the microbial communities covering nearly the total area of occurrence of $A$. willeyana, i.e. more than $20000 \mathrm{~km}$.

\section{MATERIALS AND METHODS}

\section{Sample collection}

Samples of Astrosclera willeyana were collected during SCUBA dives at depths between 4 and $23 \mathrm{~m}$ at several sites located in the western and southern Pacific Ocean, Coral Sea, and Red Sea (Table 1). Forty-two sponges were excised with chisel and hammer and transferred directly to plastic bags while underwater. Sponge samples were preserved either in silica gel (Erpenbeck et al. 2004), DMSO buffer (adapted from Seutin et al. 1991), or $95 \%$ ethanol. We describe the processing of sponge samples and DNA extractions in detail elsewhere (Karlińska-Batres \& Wörheide 2013a).

\section{Construction of 16S rRNA gene clone libraries and phylogenetic analyses}

The clone library from $A$. willeyana sample no. GW950 from Yonge Reef, GBR, is described in detail elsewhere (Karlińska-Batres \& Wörheide 2013b). A second clone library was constructed from a sample of $A$. willeyana from the Red Sea (sample no. GW1046) 
Table 1. Sample data of investigated Astrosclera willeyana specimens, with collection site details. Details of 12 previously described samples from the Great Barrier Reef (GBR), Australia, (Karlińska-Batres \& Wörheide 2013b) are not shown

\begin{tabular}{|c|c|c|c|c|c|c|}
\hline Sample no. & Location & Site & Depth (m) & Year & Latitude & Longitude \\
\hline RS1 & Red Sea & Canyon \#1 & 15 & 1992 & $28^{\circ} 30^{\prime} 20^{\prime \prime} \mathrm{N}^{\mathrm{a}}$ & $34^{\circ} 31^{\prime} 25^{\prime \prime} \mathrm{E}^{\mathrm{a}}$ \\
\hline $\mathrm{RS} 2$ & Red Sea & Canyon \#2 & 15 & 1992 & $28^{\circ} 30^{\prime} 20^{\prime \prime} \mathrm{N}^{\mathrm{a}}$ & $34^{\circ} 31^{\prime} 25^{\prime \prime} \mathrm{E}^{\mathrm{a}}$ \\
\hline RS3 & Red Sea & Canyon \#3 & 15 & 1992 & $28^{\circ} 30^{\prime} 20^{\prime \prime} \mathrm{N}^{\mathrm{a}}$ & $34^{\circ} 31^{\prime} 25^{\prime \prime} \mathrm{E}^{\mathrm{a}}$ \\
\hline RS4 & Red Sea & Canyon \#4 & 15 & 1992 & $28^{\circ} 30^{\prime} 20^{\prime \prime} \mathrm{N}^{\mathrm{a}}$ & $34^{\circ} 31^{\prime} 25^{\prime \prime} \mathrm{E}^{\mathrm{a}}$ \\
\hline GW1046 & Red Sea & Canyon \#5 & 15 & 2006 & $28^{\circ} 30^{\prime} 20^{\prime \prime} \mathrm{N}^{\mathrm{a}}$ & $34^{\circ} 31^{\prime} 25^{\prime \prime} \mathrm{E}^{\mathrm{a}}$ \\
\hline GW972 & GBR, Coral Sea & South Island \#1 & 6 & 2010 & $14^{\circ} 42^{\prime} 10^{\prime \prime} \mathrm{S}$ & $145^{\circ} 27^{\prime} 3^{\prime \prime} \mathrm{E}$ \\
\hline GW977 & GBR, Coral Sea & South Island \#2 & 6 & 2010 & $14^{\circ} 42^{\prime} 10^{\prime \prime} \mathrm{S}$ & $145^{\circ} 27^{\prime} 3^{\prime \prime} \mathrm{E}$ \\
\hline G316283 & Coral Sea & Osprey Reef & 14 & 2006 & $13^{\circ} 53^{\prime} 30^{\prime \prime} \mathrm{S}$ & $146^{\circ} 33^{\prime} 6^{\prime \prime} \mathrm{E}$ \\
\hline UF6 & French Polynesia & Tuamotus & 10 & 2005 & $14^{\circ} 58^{\prime} 60^{\prime \prime} \mathrm{S}$ & $147^{\circ} 37^{\prime} 0^{\prime \prime} \mathrm{W}$ \\
\hline UF8 & French Polynesia & Moorea & $12-16$ & 2005 & $15^{\circ} 00^{\prime} \mathrm{S}^{\mathrm{b}}$ & $140^{\circ} 00^{\prime} \mathrm{W}^{\mathrm{b}}$ \\
\hline G316176 & Guam & Haputo \#1 & $5-18$ & 2001 & $13^{\circ} 28^{\prime} \mathrm{N}^{\mathrm{b}}$ & $144^{\circ} 47^{\prime} E^{b}$ \\
\hline G316179 & Guam & Haputo \#2 & $5-18$ & 2001 & $13^{\circ} 28^{\prime} \mathrm{N}^{\mathrm{b}}$ & $144^{\circ} 47^{\prime} E^{b}$ \\
\hline GW769.7 & Palau & Siaes Tunnel \#1 & $5-18$ & 2002 & $7^{\circ} 30^{\prime} \mathrm{N}^{b}$ & $134^{\circ} 30^{\prime} E^{b}$ \\
\hline GW769.6 & Palau & Siaes Tunnel \#2 & $5-18$ & 2002 & $7^{\circ} 30^{\prime} \mathrm{N}^{\mathrm{b}}$ & $134^{\circ} 30^{\prime} E^{b}$ \\
\hline GW769.5 & Palau & Siaes Tunnel \#3 & $5-18$ & 2002 & $7^{\circ} 30^{\prime} \mathrm{N}^{\mathrm{b}}$ & $134^{\circ} 30^{\prime} E^{b}$ \\
\hline GW769.4 & Palau & Siaes Tunnel \#4 & $5-18$ & 2002 & $7^{\circ} 30^{\prime} \mathrm{N}^{\mathrm{b}}$ & $134^{\circ} 30^{\prime} E^{b}$ \\
\hline GW769.1 & Palau & Siaes Tunnel \#5 & $5-18$ & 2002 & $7^{\circ} 30^{\prime} \mathrm{N}^{b}$ & $134^{\circ} 30^{\prime} \mathrm{E}^{\mathrm{b}}$ \\
\hline G313888 & Vanuatu & Vanu Lava & $18-23$ & 1999 & $13^{\circ} 56^{\prime} 48^{\prime \prime} \mathrm{S}$ & $167^{\circ} 26^{\prime} 28^{\prime \prime} \mathrm{E}$ \\
\hline G313906 & Vanuatu & Mota Lava & 15 & 1999 & $13^{\circ} 39^{\prime} 3^{\prime \prime} \mathrm{S}$ & $167^{\circ} 39^{\prime} 14^{\prime \prime} \mathrm{E}$ \\
\hline G313935 & Vanuatu & & $5-18$ & 1999 & $16^{\circ} 00^{\prime} \mathrm{S}^{\mathrm{b}}$ & $167^{\circ} 00^{\prime} \mathrm{E}^{\mathrm{b}}$ \\
\hline JH47 & Vanuatu & Espiritu Santo \#1 & $5-18$ & & $16^{\circ} 00^{\prime} \mathrm{S}^{\mathrm{b}}$ & $167^{\circ} 00^{\prime} \mathrm{E}^{\mathrm{b}}$ \\
\hline JH23 & Vanuatu & Espiritu Santo \#2 & $5-18$ & & $16^{\circ} 00^{\prime} \mathrm{S}^{\mathrm{b}}$ & $167^{\circ} 00^{\prime} E^{\mathrm{b}}$ \\
\hline JH3 & Vanuatu & Espiritu Santo \#3 & $5-18$ & & $16^{\circ} 00^{\prime} \mathrm{S}^{\mathrm{b}}$ & $167^{\circ} 00^{\prime} \mathrm{E}^{\mathrm{b}}$ \\
\hline 102 (GW5440) & Fiji & Waya Island \#1 & 15 & 1999 & $18^{\circ} 00^{\prime} \mathrm{S}^{\mathrm{b}}$ & $175^{\circ} 00^{\prime} E^{b}$ \\
\hline 101 (GW5439) & Fiji & Waya Island \#2 & 15 & 1999 & $18^{\circ} 00^{\prime} \mathrm{S}^{\mathrm{b}}$ & $175^{\circ} 00^{\prime} E^{b}$ \\
\hline 98 (GW5436) & Fiji & Astrolabe Reef \#1 & 8 & 1998 & $18^{\circ} 00^{\prime} \mathrm{S}^{\mathrm{b}}$ & $175^{\circ} 00^{\prime} E^{b}$ \\
\hline 97 (GW5435) & Fiji & Astrolabe Reef \#2 & 6 & 1998 & $18^{\circ} 00^{\prime} \mathrm{S}^{\mathrm{b}}$ & $175^{\circ} 00^{\prime} \mathrm{E}^{\mathrm{b}}$ \\
\hline 96 (GW5434) & Fiji & Astrolabe Reef \#3 & 6 & 1998 & $18^{\circ} 00^{\prime} \mathrm{S}^{\mathrm{b}}$ & $175^{\circ} 00^{\prime} E^{b}$ \\
\hline 95 (GW5433) & Fiji & Astrolabe Reef \#4 & 15 & 1998 & $18^{\circ} 00^{\prime} \mathrm{S}^{\mathrm{b}}$ & $175^{\circ} 00^{\prime} E^{\mathrm{b}}$ \\
\hline 94 (GW5432) & Fiji & Astrolabe Reef \#5 & 15 & 1998 & $18^{\circ} 00^{\prime} S^{b}$ & $175^{\circ} 00^{\prime} E^{\mathrm{b}}$ \\
\hline
\end{tabular}

using the same procedure, including PCR amplification and sequencing of individual clones, but without the restriction digestion step (Karlińska-Batres \& Wörheide 2013b). Most 16S rRNA sequences obtained had a length of around $1500 \mathrm{bp}$.

Sequences obtained from both samples, together with the most similar sequences determined by BLAST, were imported into the ARB program (Ludwig et al. 2004) and subsequently aligned using the ARB Integrated Aligner. The resulting alignment was checked and corrected manually for alignment errors. The neighbor-joining method (Jukes-Cantor correction) was used to calculate the initial phylogenetic tree using ARB. Subsequently, the alignment was exported from the ARB database, and maximum likelihood trees were constructed using RAxML v.7.2.5 (Stamatakis 2006), using 1000 bootstrap replicates and the GTR+GAMMA model of sequence evolution. The resulting trees were visualized with the use of the FigTree v.1.3.1 program.

\section{Sponge-specific and sponge-coral clusters}

Monophyletic sponge-specific and sponge-coral clusters (SSC/SCCs) were defined based on criteria established by Hentschel et al. (2002). The BLAST search results were checked for similar sequences obtained from different sponges, corals, and nonsponge sources, which were subsequently incorporated into the ARB database and used to calculate phylogenies using neighbor-joining (ARB) and maximum likelihood methods (RAxML).

\section{Estimation of microbial diversity and statistical analysis of clone libraries}

The distance matrix generated by ARB was used to assign sequences obtained from $A$. willeyana from Yonge Reef and the Red Sea to operational taxonomic units (OTUs) using Mothur (Schloss et 
al. 2009) and with a cut-off value of 0.03 (Schloss \& Handelsman 2005). The clones from the GBR sample that were analyzed only by restriction digestion were also assigned to a corresponding OTU based on their restriction pattern. To determine the abundance and richness of the bacterial communities associated with each sponge, the Shannon and Simpson diversity indices (Spellerberg \& Fedor 2003) were calculated to describe species diversity. The Chao1 and abundance-based coverage estimator (ACE) richness index (Colwell \& Coddington 1994) were used to estimate total species richness. The LIBSHUFF method was applied to determine the significance of differences between the clone libraries (Schloss et al. 2004). Mothur was used to perform the calculations and to generate a Venn diagram to compare the richness shared between the microbial communities of both sponges. The rarefaction curves calculated with Mothur were plotted using the $\mathrm{R}$ software package (www.rproject.org).

\section{Nucleotide sequence accession numbers}

Clone sequences obtained from A. willeyana from Yonge Reef were previously deposited in an EMBL database under accession numbers HE985081 to HE985159. The sequences obtained during this study from the Red Sea specimen were deposited in the EMBL database under accession numbers HG423455 to HG423535. was used for the similarity calculations between the DGGE banding patterns. Cluster analyses were performed using the unweighted pair group method with arithmetic averages (UPGMA) to obtain similarity dendrograms.

\section{RESULTS}

\section{Clone library construction, OTU assignment, and phylogenetic analyses}

In total, 380 clones were selected from the $16 \mathrm{~S}$ rRNA clone library as amplified from Astrosclera willeyana from the Yonge Reef (GW950). From that number, 298 clones were sequenced and 9 sequences were discarded as chimeras. Through clustering of the remaining 289 clone sequences together with a single archaeal 16S rRNA sequence in Mothur, 79 OTUs were retrieved using a $97 \%$ similarity criterion. A further 82 clones were assigned to a particular OTU based on their restriction patterns. From the 16S rRNA clone library amplified from $A$. willeyana from the Red Sea (GW1046), 427 clones were selected and sequenced, and from those, 1 chimerical sequence was discarded. The remaining 426 clones were clustered into 81 OTUs using Mothur (97\% similarity criterion). The singletons constituted $32 \%$ of the clone library of $A$. willeyana from the GBR and about $37 \%$ of that from the Red Sea. The distribution of $16 \mathrm{~S}$ rRNA gene clones

\section{DGGE}

We previously described DGGE analyses of bacterial communities in 12 samples of $A$. willeyana from the GBR (Karlińska-Batres \& Wörheide 2013b). For the current project, bacterial 16S rRNA genes from 30 additional DNA extracts were analyzed using similar methods. Samples from the Red Sea were run on the same gel (Gel 1) as the previously described 12 samples from the GBR (Karlińska-Batres \& Wörheide 2013b). Gel 2 included samples from the Coral Sea (also GBR), French Polynesia, Guam, Fiji, Palau, and Vanuatu. The band-matching Dice coefficient with optimization at $0.75 \%$ and a tolerance level of $0.75 \%$
Table 2. Distribution of the 16S rRNA clones and operational taxonomic units (OTUs) defined at distance 0.03 among particular phylogenetic groups in the clone libraries obtained from the Astrosclera willeyana samples

\begin{tabular}{|c|c|c|c|c|c|c|}
\hline \multirow{2}{*}{$\begin{array}{l}\text { Phylogenetic } \\
\text { group }\end{array}$} & \multicolumn{3}{|c|}{ — Great Barrier Reef — } & \multirow[b]{2}{*}{$\begin{array}{l}\% \text { of } \\
\text { total }\end{array}$} & \multirow{2}{*}{$\begin{array}{c}\text { Red Sea } \\
\text { No. of } \\
\text { clones }\end{array}$} & \multirow[b]{2}{*}{$\begin{array}{l}\text { No. of } \\
\text { OTUs }\end{array}$} \\
\hline & $\begin{array}{l}\% \text { of } \\
\text { total }\end{array}$ & $\begin{array}{l}\text { No. of } \\
\text { clones }\end{array}$ & $\begin{array}{l}\text { No. of } \\
\text { OTUs }\end{array}$ & & & \\
\hline Chloroflexi & 41.9 & 156 & 25 & 40.8 & 174 & 27 \\
\hline Gammaproteobacteria & 13.7 & 51 & 12 & 22.3 & 95 & 17 \\
\hline Actinobacteria & 11 & 41 & 6 & 6.6 & 28 & 5 \\
\hline Acidobacteria & 7.8 & 29 & 9 & 4.9 & 21 & 5 \\
\hline Deferribacteres & 6.7 & 25 & 2 & 4.2 & 18 & 3 \\
\hline Deltaproteobacteria & 5.9 & 22 & 8 & 10.8 & 46 & 9 \\
\hline Alphaproteobacteria & 5.1 & 19 & 8 & 6.3 & 27 & 9 \\
\hline Nitrospirae & 4.3 & 16 & 1 & 2.1 & 9 & 2 \\
\hline Gemmatimonadetes & 1.9 & 7 & 3 & 1.2 & 5 & 2 \\
\hline Spirochaetes & 0.8 & 3 & 2 & 0.5 & 2 & 1 \\
\hline Poribacteria & 0.3 & 1 & 1 & - & 0 & 0 \\
\hline Cyanobacteria & 0.3 & 1 & 1 & - & 0 & 0 \\
\hline Uncertain affiliation & - & 0 & 0 & 0.2 & 1 & 1 \\
\hline \multirow[t]{2}{*}{ Archaea } & 0.3 & 1 & 1 & - & 0 & 0 \\
\hline & & 372 & 79 & & 426 & 81 \\
\hline
\end{tabular}


among the OTUs is summarized in Fig. S1 in the Supplement at www.int-res.com/articles/suppl/a074p143 _supp.pdf. Both specimens of $A$. willeyana revealed 16S rRNA gene sequences classified as Chloroflexi, Gammaproteobacteria, Actinobacteria, Acidobacteria, Deferribacteres, Deltaproteobacteria, Alphaproteobacteria, Nitrospirae, and Spirochaetes (Table 2). Additionally, the GBR specimen exposed sequences belonging to Poribacteria, Cyanobacteria, and Crenarchaeota; the specimen from the Red Sea also revealed a single sequence of uncertain affiliation, which differed from bacteria from any described phylum. No PCR products were obtained for A. willeyana from the Red Sea (sample no. GW1046) using specific $16 \mathrm{~S}$ rRNA archaeal primers. The phylogenetic trees present the OTUs from both A. willeyana with the nearest similar sequences assigned to Chloroflexi (Fig. 1) and Proteobacteria (Fig. 2A,B), and to all other phyla (Fig. 3).

\section{Closest relatives}

Based on the BLAST results, A. willeyana from the GBR had a slightly higher fraction of OTUs that were closely related to other previously described spongeor coral-derived microbial sequences, i.e. $94 \%$ (74 out of 79 defined OTUs) in comparison with the Red Sea specimen of $88 \%$ ( 71 out of 81 defined OTUs). Both sponges revealed similar fractions of OTUs with closest relatives obtained from corals (GBR $11 \%$, Red Sea $10 \%)$. A. willeyana from the GBR had a distinctly lower ratio $(6 \%)$ of OTUs, with closest relatives derived from the environment (Red Sea specimen $12 \%$ ). Only A. willeyana from the Red Sea revealed 2 OTUs with a closest sequence derived from a validly described organism $(94 \%$ similarity with an isolate of the sponge Pseudovibrio denitrificans and $99 \%$ similarity with an isolate of the copepod Pseudoalteromonas piscicida), as well as 1 OTU with a closely related (99\%) 16S rRNA sequence of Pseudomonas sp. isolated from costal sediment water. The results of the BLAST search are summarized in Tables S1 \& S2 in the Supplement.

\section{Shared OTUs}

Cloned $A$. willeyana samples shared 31 OTUs, which represented $61 \%$ of the GBR clones $(n=227)$ and $55 \%$ of the Red Sea clones $(\mathrm{n}=236)$. The largest number of shared OTUs belonged to the phylum Proteobacteria (12 OTUs) and Chloroflexi (10 OTUs). One shared
OTU, classified as Actinobacteria, revealed 29 clones from the GBR specimen and 17 clones from the Red Sea specimen. Another shared OTU, classified as Chloroflexi, revealed 27 clones from the Red Sea specimen and only 5 clones from the GBR specimen. Only 1 shared OTU with a high number of clones, classified as Deferribacteres, revealed similar numbers of clones $(n=15)$ by both specimens. In the phylogenetic trees (Figs. 1-3), the shared OTUs are indicated as clone names in brackets.

\section{SSC/SCC}

From both coralline sponges, $67 \%$ of the OTUs closely related to other sponge- or coral-derived sequences fell into 49 SSC/SCCs (GBR: 53 OTUs, Red Sea: 54 OTUs). The Astrosclera specimens shared 33 SSC/SCCs and, additionally, 10 OTUs of the GBR specimen were assigned to 10 individual SSC/SCCs, and 10 OTUs of the Red Sea specimen were assigned to 5 individual SSC/SCCs.

\section{Microbial diversity and community structure}

An analysis of the clone library showed that the microbial community of $A$. willeyana from the GBR was slightly more diverse due to the presence of Poribacteria, Cyanobacteria, and Archaea; however, members of an unclassified clade were found only in A. willeyana from the Red Sea (Table 2). Furthermore, both communities varied notably in the abundance of Gammaproteobacteria (14\% for the GBR and $22 \%$ for the Red Sea) and Deltaproteobacteria (6\% for the GBR and $11 \%$ for the Red Sea) as well as slightly in the abundance of Actinobacteria and Acidobacteria $(11 \%$ and $8 \%$ for the GBR and $7 \%$ and $5 \%$ for the Red Sea, respectively). In both communities, the most abundant taxa were Chloroflexi (43\% for the GBR and $41 \%$ for the Red Sea; Table 2). LIBSHUFF statistical analysis of the libraries (Schloss et al. 2004) confirmed a highly significant difference between the microbial communities of the $2 \mathrm{~A}$. willeyana samples $(\mathrm{p}<0.0001)$. A Venn diagram of the OTU distributions at a distance of 0.03 revealed that of the 129 defined and different OTUs, $24 \%$ were shared between the communities of A. willeyana from the GBR and Red Sea.

A slightly higher Shannon-Wiener index for A. willeyana from the GBR confirmed a greater complexity of its microbiota. However, the Simpson index, which gives a strong weighting to the dominants, showed 


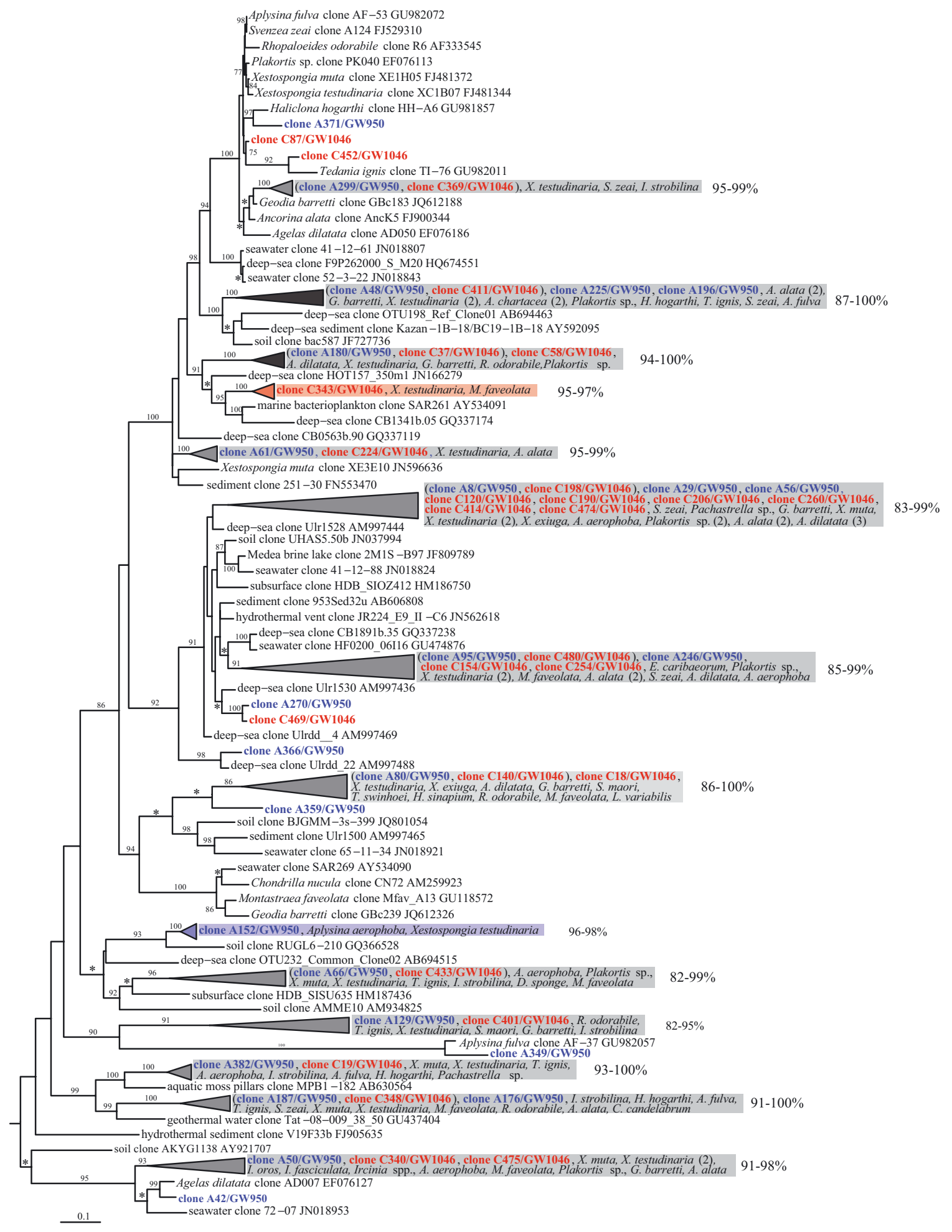

Fig. 1. Maximum-likelihood phylogeny of Astrosclera willeyana-derived 16S rRNA sequences affiliated with the phylum Chloroflexi, with the next most similar sequences obtained from other sponges or corals and from the environment. Reference sequences are listed with their GenBank numbers. Bold text signifies clones obtained during this study from $A$. willeyana samples (blue from the Great Barrier Reef, Australia [GBR]; red from the Red Sea); clone names in brackets indicate shared operational taxonomic units (OTUs). Shaded boxes represent sponge-specific clusters: grey - clusters shared, blue with the clones from the GBR, red with the clones from the Red Sea; numbers in parentheses next to sponge names indicate the number of sequences per sponge. Bootstrap analysis was based on 1000 replicates; support values $70-85 \%$ are indicated by asterisks. Scale bar signifies $10 \%$ sequence divergence 


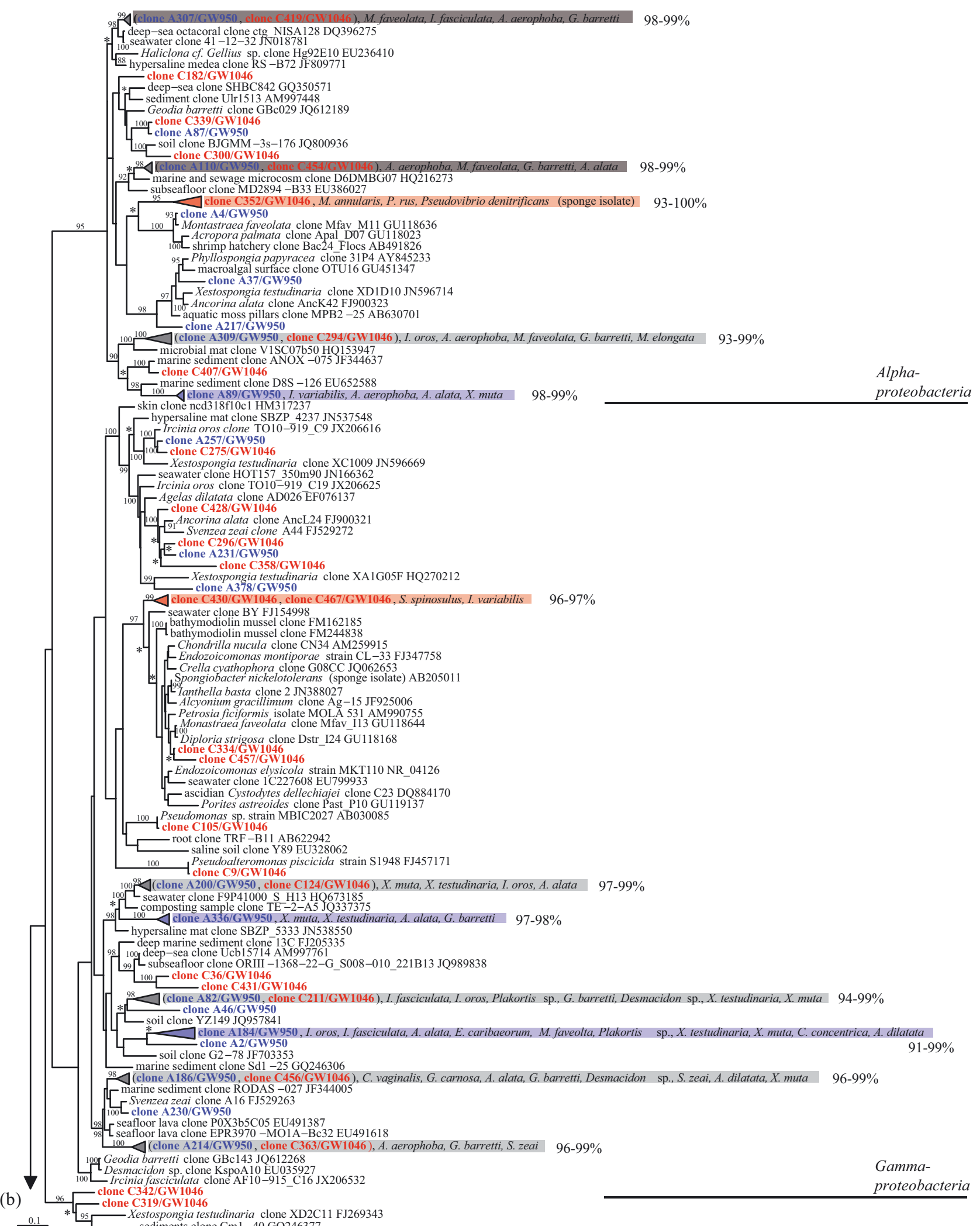

Fig. 2. (continued on next page) Maximum-likelihood phylogeny of Astrosclera willeyana-derived 16S rRNA sequences affiliated with the phylum Proteobacteria, with the next most similar sequences obtained from other sponges or corals and from the environment. The tree is displayed as 2 subtrees $(a, b)$; arrows go to the remaining tree parts. Reference sequences are listed with their GenBank numbers. Other details as in Fig. 1 
(a)

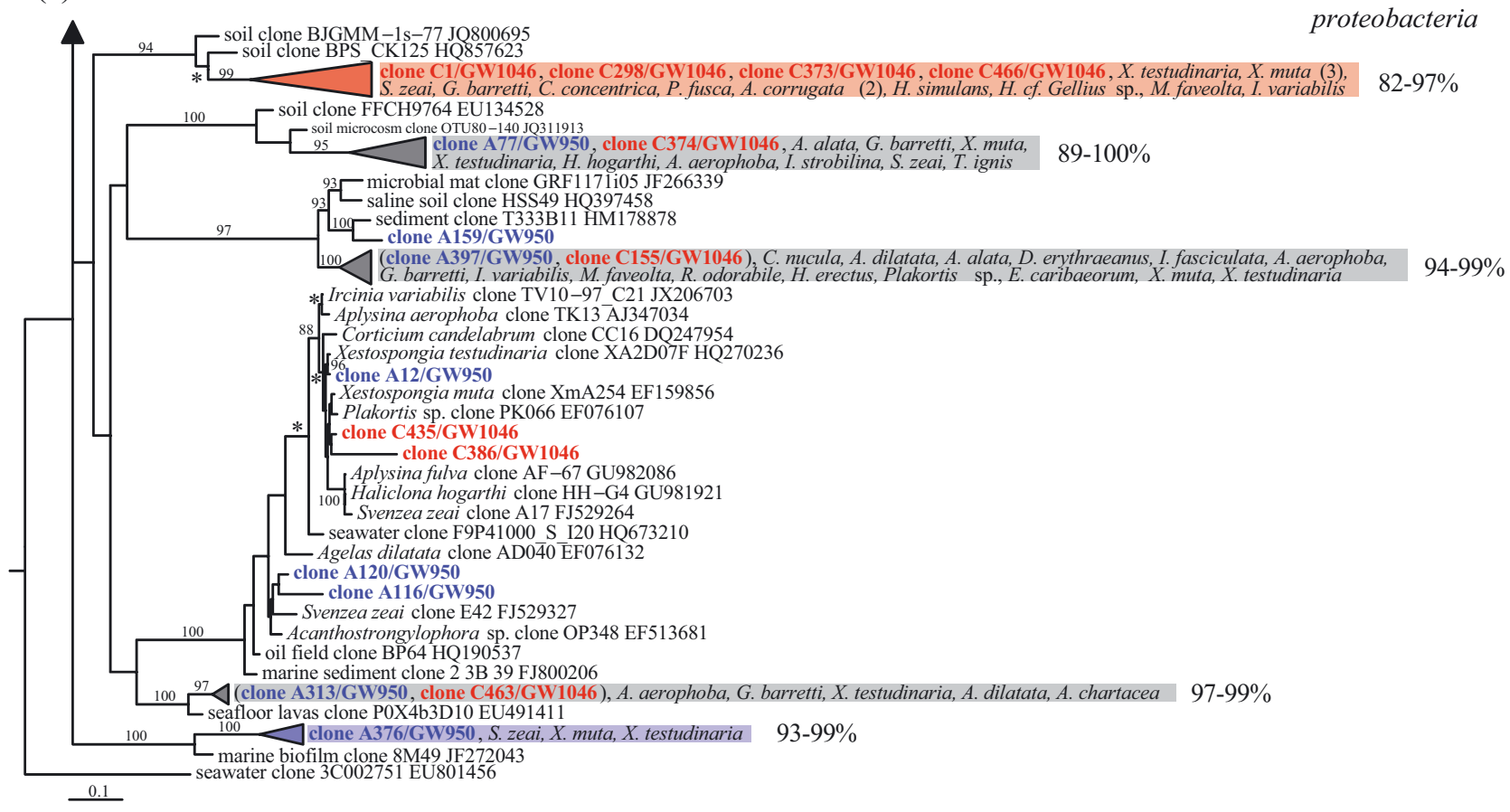

Fig. 2 (continued)

no differences between the 2 investigated communities. According to the Chao1 index and the ACE (Table 3 ), we sequenced $80 \%$ of the predicted number of microbial species in the community associated with $A$. willeyana from the GBR; for A. willeyana from the Red Sea, the values given by the estimators differed (65\% according to the Chao1 index and $72 \%$ for $\mathrm{ACE}$ ) and indicated a less effective sampling. In contrast, the rarefaction curves for the Red Sea sample calculated for the $0.03,0.05$, and 0.1 cutoff criteria indicated a more successful sampling than was denoted by the Chao1 and ACE estimators (Table 3), as they almost reached saturation (Fig. 4). Despite these differences, the sampled diversity provides a comprehensive picture of the core microbial communities of both coralline sponges (Schmitt et al. 2011).

\section{DGGE}

We found very complex DGGE banding profiles in all samples with numerous bands: the samples from Fiji and the Red Sea showed the lowest average number of bands (26 bands from the Red Sea and Waya Island, Fiji, and 27 bands from the Astrolabe Reef, Fiji); the Haputo, Guam, samples showed the highest average number of bands (34). On Gel 1, we detected 73 different band types, with only 2 predominant bands, which were present in all of the Astrosclera samples, and another 4 bands, which were missing from 4 individual samples. On Gel 2, we found 84 different band types, and here also only 2 bands were present in all 25 samples, and a further 2 in 24 samples (the banding profiles of both gels are available in Fig. S2 in the Supplement). Due to the difficulty of making an accurate comparison between the gels, we performed the cluster analysis separately. However, on both gels, the samples were clustered together according to their geographical origin (Fig. 5). Analysis of Gel 1 demonstrated a clear division between North GBR (NGBR), South GBR (S-GBR), and GBR inshore samples with separation of the Red Sea. Analysis of Gel 2 demonstrated a definite division between the microbial communities associated with $A$. willeyana from Palau, the Coral Sea, and the South Pacific (French Polynesia), whereas within the Western Pacific, the microbial communities of $A$. willeyana sampled to the north of the largest Fijian island (Viti Levu), viz. Guam, Vanuatu, and Waya Island, clustered together and formed a sister group to the specimens from the Astrolabe Reef (to the south of Viti Levu; Fig 5). 


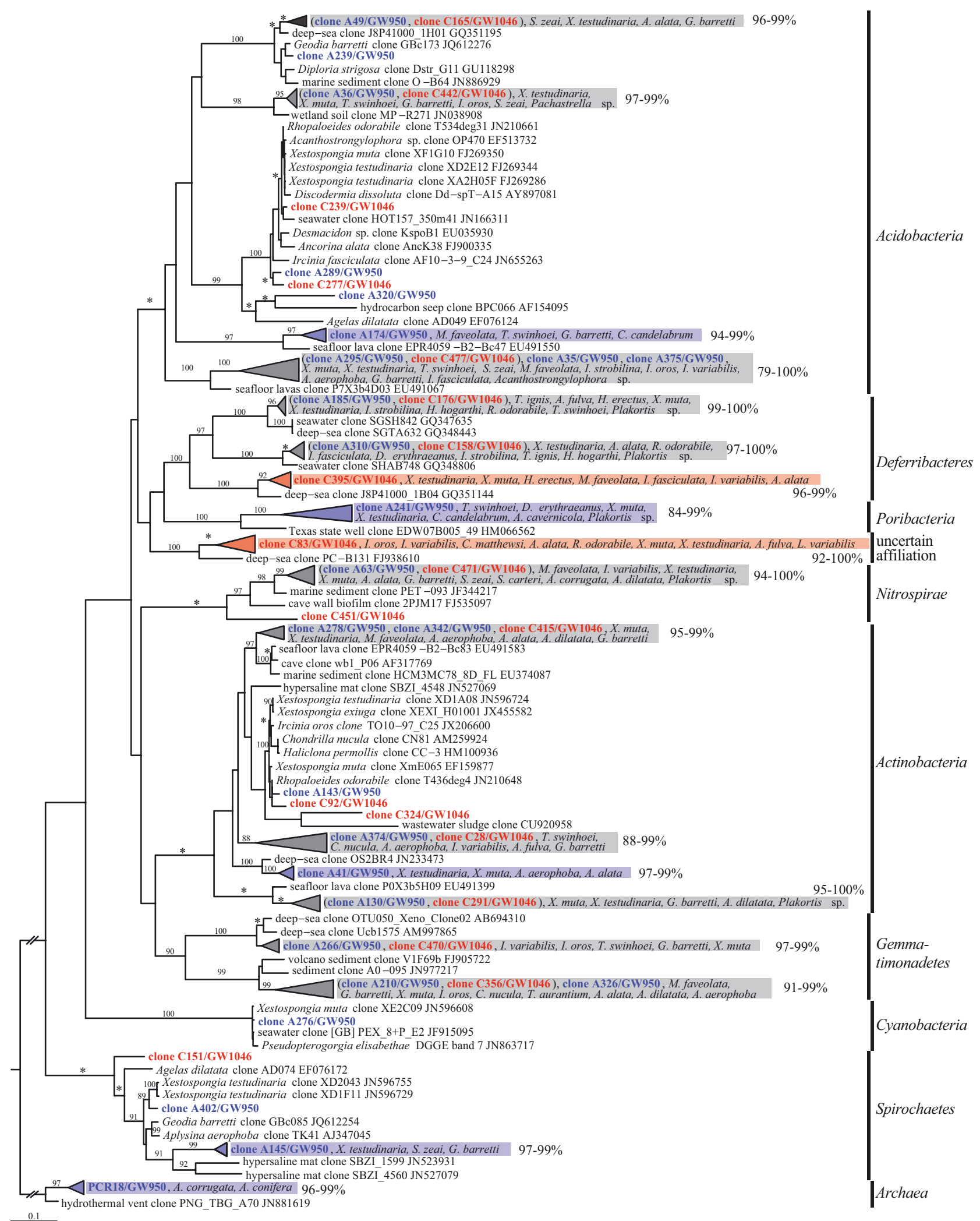

Fig. 3. Maximum-likelihood phylogeny of Astrosclera willeyana-derived 16S rRNA sequences affiliated with several phyla, with the next most similar sequences obtained from other sponges or corals and from the environment. Reference sequences are listed with their GenBank numbers. Other details as in Fig. 1 
Table 3. Diversity analysis of the 16S rRNA gene clone libraries constructed at distance 0.03 for the Astrosclera willeyana samples. Lower and upper $95 \%$ confidence intervals are shown in parentheses where available. OTU: operational taxonomic unit, ACE: abundance-based coverage estimator

\begin{tabular}{|c|c|c|c|c|c|c|}
\hline Sample source & No. of clones & No. of OTUs & Chao estimate & $\mathrm{ACE}$ & Shannon index & Simpson index \\
\hline Great Barrier Reef & 372 & 79 & $\begin{array}{c}100 \\
(87-136)\end{array}$ & $\begin{array}{c}100 \\
(89-125)\end{array}$ & $\begin{array}{c}3.88 \\
(3.77-3.98)\end{array}$ & $\begin{array}{c}0.028 \\
(0.023-0.033)\end{array}$ \\
\hline Red Sea & 426 & 81 & $\begin{array}{c}124 \\
(98-191)\end{array}$ & $\begin{array}{c}113 \\
(96-148)\end{array}$ & $\begin{array}{c}3.84 \\
(3.73-3.94)\end{array}$ & $\begin{array}{c}0.029 \\
(0.025-0.033)\end{array}$ \\
\hline
\end{tabular}

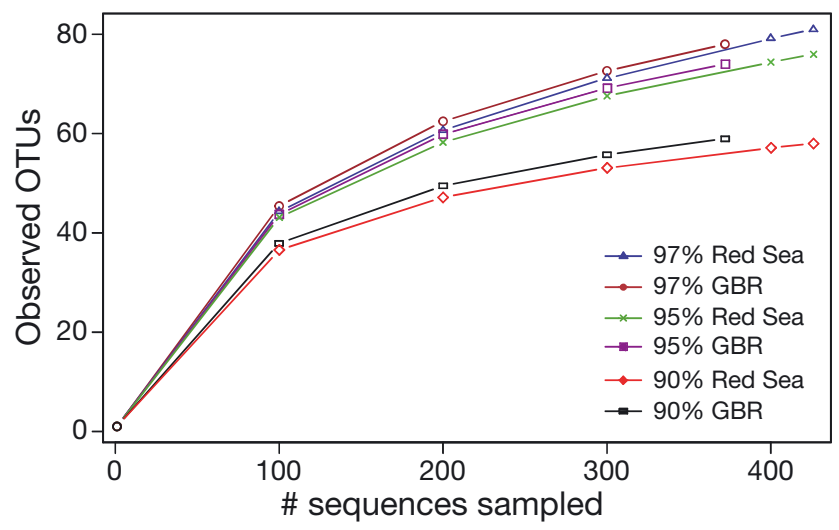

Fig. 4. Rarefaction curves for the 16S rRNA gene sequences obtained from Astrosclera willeyana from the Great Barrier Reef (GBR), Australia, and from the Red Sea. Operational taxonomic units (OTUs) were defined at the 97, 95, and $90 \%$ similarity criteria

\section{DISCUSSION}

To our knowledge, this is the first study to address the diversity and composition of the microbial community associated with coralline sponges from the Red Sea, and it is the first investigation of the microbiota of Astrosclera willeyana over its wide IndoPacific range, from the Red Sea to the central Pacific. The 16S rRNA gene-based characterization of the microbial diversity of $A$. willeyana from the Red Sea revealed a highly complex and rich symbiotic community, including representatives of 8 bacterial phyla and 1 uncertain bacterial group. A comparison with a previously assessed $16 \mathrm{~S}$ clone library of A. willeyana from the GBR (Karlińska-Batres \& Wörheide 2013b) showed significant differences in community composition as well as some similarities between the microbiota. The DGGE analysis of bacterial 16S rRNA genes obtained from A. willeyana specimens covering the vast area of their appearance confirmed a high microbial diversity in all of the investigated samples and revealed a closer association between the microbial communities with respect to their geographical provenance.
The Red Sea, with its perennial high temperatures and high salinity of seawater bodies, constitutes a unique ecosystem on a global scale and a natural habitat for corals and sponges (Ilan et al. 2004). More than 2 decades of research on Red Sea sponges have brought significant findings regarding natural products and bioactive compounds and their ecological importance to coral reefs (Ilan et al. 2004). However, from among the ca. 240 sponge species recorded from the Red Sea (Radwan et al. 2010), the microbial communities of only a few species have been investigated to date (Hentschel et al. 2002, Oren et al. 2005, Radwan et al. 2010, Lee et al. 2011). Our investigations on the microbial community of $A$. willeyana gave the first ever insight into the microbiota of coralline sponges from the Red Sea. This was also the first study on Red Sea sponges with a very high number of selected clones. Phyla commonly associated with marine sponges dominated in the microbial community of A. willeyana (Taylor et al. 2007, Webster \& Taylor 2012); however, these phyla were significantly differentiated from the communities associated with other Red Sea sponges that had previously been studied using a similar 16S rRNA cloning approach (Hentschel et al. 2002, Oren et al. 2005, Radwan et al. 2010, Lee et al. 2011). The level of diversity could be compared with the microbiota of Red Sea Hyrtios erectus (42 selected clones), but this symbiotic community revealed members of Bacteroidetes, Firmicutes, TM7, and Betaproteobacteria (Radwan et al. 2010), and lacked bacteria of an uncertain affiliation that were found in the Red Sea A. willeyana. In the same study, Radwan et al. (2010) also investigated the microbial community from Amphimedon sp. (39 clones), but this microbiota revealed strikingly lower diversity and only slight overlap with $A$. willeyana. The microbial diversity associated with A. willeyana also significantly exceeded the diversity of the Red Sea sponge Diacarnus erythraenus (37 clones) dominated by Cyanobacteria (Bergman et al. 2011). However, if we also consider sequences obtained from larvae (38 clones) and from isolates from adult 
sponges (88) and larvae (40), the magnitude of diversity increases considerably (Bergman et al. 2011), which makes the results comparable to those of the community obtained from A. willeyana. The first pyrosequencing analysis of microbiota associated with 3 Red Sea sponges-Hyrtios erectus, Stylissa carteri, and Xestospongia testudinaria (Lee et al. 2011) - significantly expanded the magnitude of microbial diversity in sponges from this biogeographic region; however, the differences in the level of phylogenetic resolution between the techniques that were used made a direct comparison of this study with our analyses difficult. One of the striking findings of the study by Lee et al. (2011) was a very high abundance of Archaea - up to 300 archaeal species estimated from a single sponge (up to 100 OTUs revealed). A. willeyana from the Red Sea

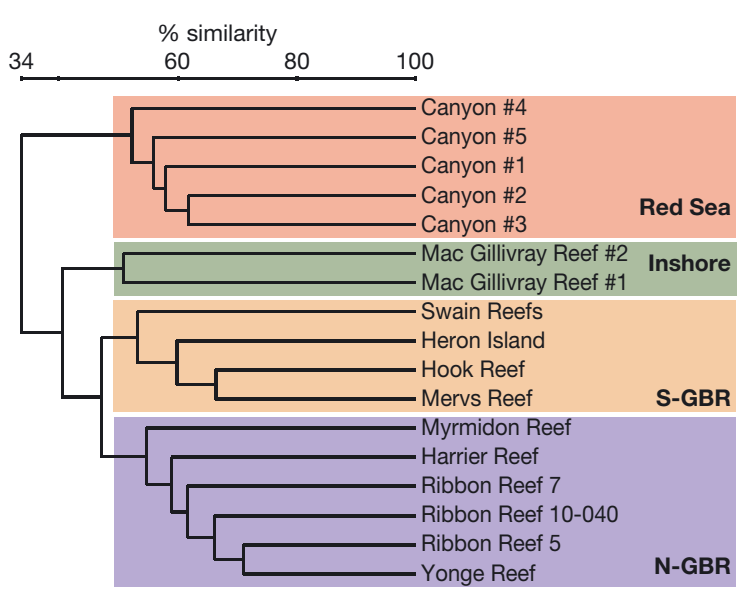

Gel 1

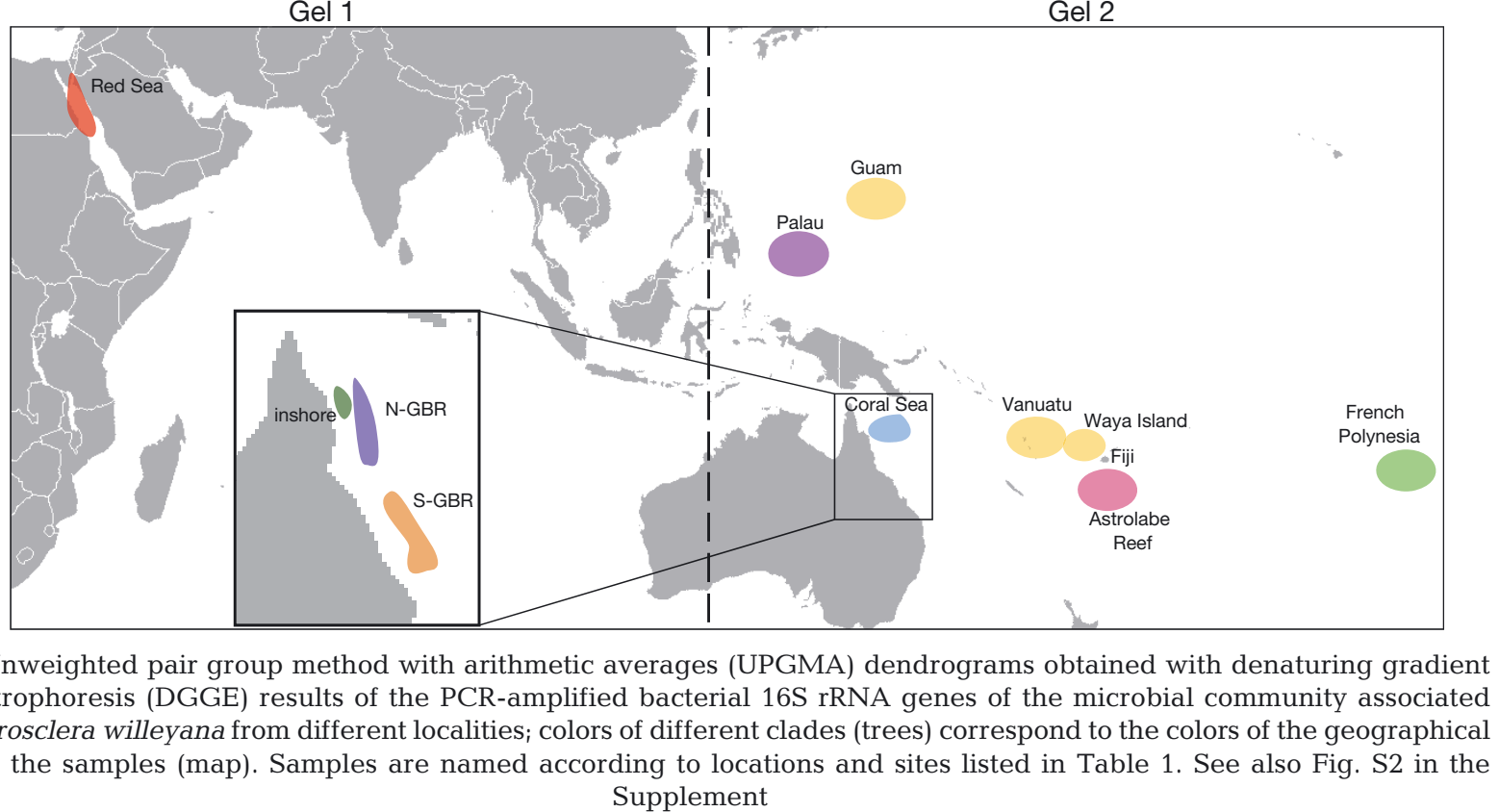

Fig. 5. Unweighted pair group method with arithmetic averages (UPGMA) dendrograms obtained with denaturing gradient gel electrophoresis (DGGE) results of the PCR-amplified bacterial 16S rRNA genes of the microbial community associated with Astrosclera willeyana from different localities; colors of different clades (trees) correspond to the colors of the geographical origin of the samples (map). Samples are named according to locations and sites listed in Table 1. See also Fig. S2 in the

lacked Archaea entirely. Interestingly, the clone library of $A$. willeyana from the GBR revealed only a single archaeal OTU that was similar to a clone library constructed from another coralline sponge, Vaceletia crypta, which co-occurs and was sampled from the same site (Yonge Reef, GBR) (KarlińskaBatres \& Wörheide 2013a). These findings raise the question as to whether coralline sponges indeed form very limited associations with Archaea.

The comparison of $16 \mathrm{~S}$ rRNA clone libraries obtained from $A$. willeyana from the Red Sea and from the GBR (Karlińska-Batres \& Wörheide 2013b) showed substantial differences in the structure of the microbial communities. The microbiota associated with the

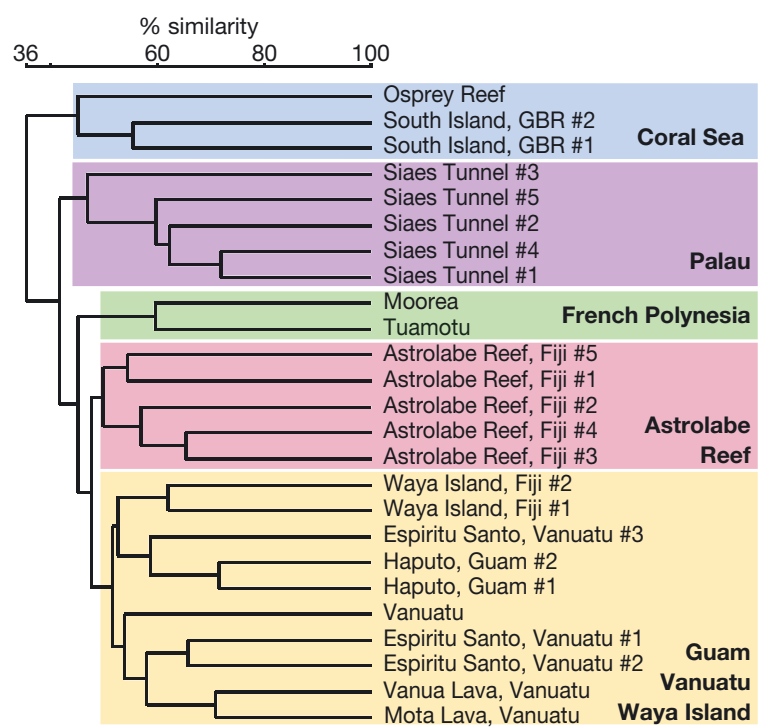

Gel 2 
GBR specimen revealed a more complex structure. The microbial communities differed in terms of abundance of some major groups (Gammaproteobacteria, Deltaproteobacteria, Actinobacteria, and Acidobacteria), which impact host metabolism and health (Taylor et al. 2007, Webster \& Taylor 2012). Also, the presence of some minor members of the communities (Poribacteria, Cyanobacteria, Archaea, and an unclassified clade) distinguished the microbiota of the 2 Astrosclera specimens. We have previously discussed the putative functions of the phylogenetic groups in A. willeyana (Karlińska-Batres \& Wörheide 2013b). Notwithstanding, the comparison of the 16S rRNA clone libraries also showed identical fractions of clones from both communities in the SSC/SCC, thus confirming the uniqueness of symbiotic associations in these sponges. According to Shade \& Handelsman (2012), an abundant microorganism that is shared among all samples within a given habitat must play a significant function in the community. Therefore, recognizing core microbiota (microbes that are common to 2 or more samples) in complex microbial habitats is the first step in understanding systems ecology (Shade \& Handelsman 2012, Webster et al. 2013). Most studies have compared the microbial communities of sponges from the same geographical region or sea (Erwin et al. 2012, Schmitt et al. 2012, Webster et al. 2013). A study of 13 GBR sponge species revealed a high core microbiome within each species but a low microbiome shared between the species; a maximum of 5 sponge species shared OTUs, and $91 \%$ of the OTUs were species-specific (Webster et al. 2013). In another study of 3 sympatric Mediterranean Ircinia sp., Erwin et al. (2012) identified host species-specific OTUs, OTUs shared between the 2 most phylogenetically related species, and OTUs common to 2 species sharing the same cryptic habitat. These results suggested that hostspecific factors have an impact on structuring microbial symbiont communities (Erwin et al. 2012). Montalvo \& Hill (2011) compared, for the first time, the microbial symbionts of 2 closely related sponges from different oceans and revealed that the bacterial communities associated with $X$. muta and $X$. testudinaria were specific to each of the sponge species and to the genus Xestospongia. Our results are comparable with the study on Xestospongia spp. (Montalvo \& Hill 2011), since the investigated A. willeyana samples from the GBR and Red Sea shared 31 OTUs as defined based on the 0.03 similarity criterion which grouped over half of both clone libraries. However, despite the fact that more clones were selected from the Red Sea specimen, we detected less diversity (predicted $65 \%$ of OTUs). Hence, Red Sea A. willeyana might harbor more abundant and heterogeneous microbiota; therefore, although our results indicate high species-specific associations in this coralline sponge, a further investigation of samples is necessary to confirm the host-specific nature of $A$. willeyana microbial communities.

The DGGE analysis of 42 microbial communities of A. willeyana sampled from the widespread area of the species' occurrence, from the Red Sea to French Polynesia, confirmed both a high abundance and complex composition in all microbial communities. Moreover, the results exhibited a closer relationship between microbial communities depending on geographical origin, which was similar to observations in samples from the GBR (Karlińska-Batres \& Wörheide 2013b). We (Karlińska-Batres \& Wörheide 2013b) previously suggested that the split between the southern and northern GBR microbial communities associated with $A$. willeyana might be an additional indicator of the existence of cryptic species (Wörheide 1998, 2006, Wörheide et al. 2002a). In this study, not only on a small scale (GBR) but also across the wide range of $A$. willeyana in the Indo-Pacific, the microbial communities derived from specimens obtained from geographically closer populations clustered together (Fig. 5), partly confirming these assumptions. The present data support the separation of a distinct Red Sea population of $A$. willeyana, as has been primarily evidenced by analyses of ITS and COI (Wörheide et al. 2002a, Wörheide 2006). However, the separation of microbial communities from the Coral Sea and Palau, together with the clustering of microbial communities from Guam with microbiota of A. willeyana from Vanuatu and Waya Island (Fiji), as well as a clear split of the Astrolabe Reef population from the rest of Fiji, suggests closer affiliation of geographically more distant populations. This pattern could be explained by ancient gene flow regimes determined by historical events that were controlled by different current systems during low sea levels (Benzie 1999, Wörheide et al. 2002a), as was evidenced for some other coral reef organisms, such as the sponge Leucetta 'chagosensis,' starfishes Acanthaster plancii and Linckia levigata, and the giant clam Tridacna gigas (Benzie 1994, 1999, Wörheide et al. 2002b).

Our study demonstrates the high diversity of microorganisms associated with A. willeyana from the Indo-Pacific. We cloned single samples from the GBR (Karlińska-Batres \& Wörheide 2013b) and from the Red Sea, but by selecting an exceptionally high number of clones we provided a comprehensive picture of 
the core microbial community of the investigated $A$. willeyana, which was complemented through the application of DGGE to analyze numerous samples. Although we cannot rule out completely that differences in the composition of the microbiota between the Red Sea and the Great Barrier Reef specimens may be influenced by seasonal variation, it is unlikely - due to the large amount of bacteria residing inside A. willeyana (up to $70 \%$ of the biomass of the sponge, Wörheide 1998) — that a significant proportion of rRNA gene sequences belong to plankton bacteria captured by the choanocytes, skewing our results. Moreover, most of the $16 \mathrm{~S}$ rRNA sequences were highly similar to sequences derived from microorganisms found in other sponges and confirmed as symbiotic (Taylor et al. 2007, Webster \& Taylor 2012). Therefore, we consider that the consistency of the microbiota between the 5 Red Sea $A$. willeyana specimens, as revealed by DGGE analysis, indicates that its microbial community is likely to be representative of other A. willeyana specimens from that location and supports the more detailed subsequent sequencing analysis of the single individual.

The absence (Red Sea) or low occurrence (GBR) of Archaea and Poribacteria is surprising. Future studies with specific primers could provide more insight into the diversity of these phylogenetic groups. However, another coralline sponge, Vaceletia crypta, which co-occurs and was sampled from the same site (Yonge Reef, GBR), showed similar results (KarlińskaBatres \& Wörheide 2013a). Furthermore, exploring the differences between the microbial communities of these 2 coralline sponges could offer more insight into the microbial associations that are specific to coralline sponges.

Acknowledgements. Funding for this study was provided by the German Research Foundation (DFG-Wo896/7-1). We are very grateful to Sergio Vargas for help with data analysis. We thank Volker Glöckner for support with DGGE software and analysis.

\section{LITERATURE CITED}

Benzie JAH (1994) Patterns of gene flow in the Great Barrier Reef and Coral Sea. In: Beaumont AR (ed) Genetics and evolution of aquatic organisms. Chapman \& Hall, London, p 67-79

Benzie JAH (1999) Genetic structure of coral reef organisms: ghosts of dispersal past. Am Zool 39:131-145

> Bergman O, Haber M, Mayzel B, Anderson MA, Shpigel M, Hill RT, Ilan M (2011) Marine-based cultivation of Diacarnus sponges and the bacterial community composition of wild and maricultured sponges and their larvae. Mar Biotechnol 13:1169-1182
Chombard C, Boury-Esnault N, Tillier A, Vacelet J (1997) Polyphyly of 'Sclerosponges' (Porifera, Demospongiae) supported by $28 \mathrm{~S}$ ribosomal sequences. Biol Bull (Woods Hole) 193:359-367

> Colwell RK, Coddington JA (1994) Estimating terrestrial biodiversity through extrapolation. Philos Trans R Soc Lond B Biol Sci 345:101-118

Erpenbeck D, McCormack GP, Breeuwer JA, van Soest RW (2004) Order level differences in the structure of partial LSU across demosponges (Porifera): new insights into an old taxon. Mol Phylogenet Evol 32:388-395

> Erwin PM, López-Legentil S, González-Pech R, Turon X (2012) A specific mix of generalists: bacterial symbionts in Mediterranean Ircinia spp. FEMS Microbiol Ecol 79: 619-637

Hentschel U, Hopke J, Horn M, Friedrich A, Wagner M, Hacker J, Moore B (2002) Molecular evidence for a uniform microbial community in sponges from different oceans. Appl Environ Microbiol 68:4431-4440

> Ilan M, Gugel J, Van Soest RWM (2004) Taxonomy, reproduction and ecology of new and known Red Sea sponges. Sarsia 89:388-410

Karlińska-Batres K, Wörheide G (2013a) Microbial diversity in the coralline sponge Vaceletia crypta. Antonie Leeuwenhoek 103:1041-1056

Karlińska-Batres K, Wörheide G (2013b) Phylogenetic diversity and community structure of the symbionts associated with the coralline sponge Astrosclera willeyana of the Great Barrier Reef. Microb Ecol 65: $740-752$

Lee O, Wang Y, Yang J, Lafi F, Al-Suwailem A, Qian P (2011) Pyrosequencing reveals highly diverse and species-specific microbial communities in sponges from the Red Sea. ISME J 5:650-664

Ludwig W, Strunk O, Westram R, Richter L, Meier H (2004) ARB: a software environment for sequence data. Nucleic Acids Res 32:1363-1371

> Montalvo NF, Hill RT (2011) Sponge-associated bacteria are strictly maintained in two closely-related but geographically distant sponge hosts. Appl Environ Microbiol 77: 7207-7216

> Oren M, Steindler L, Ilan M (2005) Transmission, plasticity and the molecular identification of cyanobacterial symbionts in the Red Sea sponge Diacarnus erythraenus. Mar Biol 148:35-41

Radwan M, Hanora A, Zan J, Mohamed NM, Abo-Elmatty DM, Abou-El-Ela SH, Hill RT (2010) Bacterial community analyses of two Red Sea sponges. Mar Biotechnol 12: 350-360

Reitner J (1992) 'Coralline Spongien'. Der Versuch einer phylogenetisch taxonomischen Analyse. Berl Geowiss Abh E Paläobiol 1:1-352

Reitner J, Wörheide G, Thiel V, Gautret P (1996) Reef caves and cryptic habitats of Indo-Pacific reefs; distribution patterns of coralline sponges and microbialites. In: Reitner J, Neuweiler F, Gunkel F (eds) Global and regional controls on biogenic sedimentation. I. Reef evolution. Research Reports. Göttinger Arbeiten zur Geologie und Palaeontologie, Sonderband 2. Geologisches Institut der Georg-August-Universität, Göttingen, p 91-100

Schloss PD, Handelsman J (2005) Introducing DOTUR, a computer program for defining operational taxonomic units and estimating species richness. Appl Environ Microbiol 71:1501-1506 
Schloss PD, Larget BR, Handelsman J (2004) Integration of microbial ecology and statistics: a test to compare gene libraries. Appl Environ Microbiol 70:5485-5492

Schloss PD, Westcott SL, Ryabin T, Hall JR and others (2009) Introducing mothur: open-source, platform-independent, community-supported software for describing and comparing microbial communities. Appl Environ Microbiol 75:7537-7541

Schmitt S, Deines P, Behnam F, Wagner M, Taylor MW (2011) Chloroflexi bacteria are more diverse, abundant, and similar in high than in low microbial abundance sponges. FEMS Microbiol Ecol 78:497-510

Schmitt S, Tsai P, Bell J, Fromont J and others (2012) Assessing the complex sponge microbiota: core, variable and species-specific bacterial communities in marine sponges. ISME J 6:564-576

Seutin G, White BN, Boag PT (1991) Preservation of avian blood and tissue samples for DNA analysis. Can J Zool 69:82-90

Shade A, Handelsman J (2012) Beyond the Venn diagram: the hunt for a core microbiome. Environ Microbiol 14: $4-12$

Simister RL, Deines P, Botté ES, Webster N, Taylor M (2012) Sponge-specific clusters revisited: a comprehensive phylogeny of sponge-associated microorganisms. Environ Microbiol 14:517-524

Spellerberg I, Fedor P (2003) A tribute to Claude Shannon (1916-2001) and a plea for more rigorous use of species richness, species diversity and the 'Shannon-Wiener' Index. Glob Ecol Biogeogr 12:177-179

Stamatakis A (2006) RAxML-VI-HPC: maximum likelihoodbased phylogenetic analyses with thousands of taxa and mixed models. Bioinformatics 22:2688-2690

Taylor MW, Radax R, Steger D, Wagner M (2007) Spongeassociated microorganisms: evolution, ecology, and biotechnological potential. Microbiol Mol Biol Rev 71: 295-347

Taylor MW, Tsai P, Simister RL, Deines P and others (2013) 'Sponge-specific' bacteria are widespread (but rare) in diverse marine environments. ISME J 7:438-443

USBGN (United States Board on Geographic Names) (1988) Gazetteer of conventional names: names approved by the United States Board on Geographic Names, 3rd edn. Defense Mapping Agency, Washington, DC

Vacelet J (1981) Éponges hypercalcifiées ('Pharétronides',

Editorial responsibility: Tom Fenchel,

Helsingør, Denmark
'Sclérosponges') des cavités des récifs coralliens de Nouvelle-Calédonie. Bull Mus Natl Hist Nat 4A 3:313-351

Vacelet J (1985) Coralline sponges and the evolution of Porifera. In: Morris SC, George JD, Gibson R, Platt HM (eds) The origin and relationships of lower invertebrates. Clarendon Press, Oxford, p 1-13

Webster NS, Taylor MW (2012) Marine sponges and their microbial symbionts: love and other relationships. Environ Microbiol 14:335-346

> Webster NS, Taylor MW, Behnam F, Lücker S and others (2010) Deep sequencing reveals exceptional diversity and modes of transmission for bacterial sponge symbionts. Environ Microbiol 12:2070-2082

Webster NS, Botté ES, Soo RM, Whalan S (2011) The larval sponge holobiont exhibits high thermal tolerance. Environ Microbiol Rep 3:756-762

> Webster NS, Luter HM, Soo RM, Botté ES, Simister RL, Abdo D, Whalan S (2013) Same, same but different: symbiotic bacterial associations in GBR sponges. Front Microbiol 3: 444

Wilkinson CR (1984) Immunological evidence for the Precambrian origin of bacterial symbioses in marine sponges. Proc R Soc Lond B Biol Sci 220:509-518

Wörheide G (1998) The reef cave dwelling ultraconservative coralline demosponge Astrosclera willeyana Lister 1900 from the Indo-Pacific. Facies 38:1-88

Wörheide G (2006) Low variation in partial cytochrome oxidase subunit I (COI) mitochondrial sequences in the coralline demosponge Astrosclera willeyana across the Indo-Pacific. Mar Biol 148:907-912

Wörheide G, Degnan BM, Hooper JNA, Reitner J (2002a) Phylogeography and taxonomy of the Indo-Pacific reef cave dwelling coralline demosponge Astrosclera willeyana: new data from nuclear ITS sequences. In: Moosa KM, Soemodihardjo S, Soegiarto A, Romimohtarto K, Nontji A, Soekarno, Suharsono (eds) Proc 9th Int Coral Reef Symp. Ministry for Environment, Indonesian Institute of Sciences, International Society for Reef Studies, Jakarta, p 339-346

> Wörheide G, Hooper JNA, Degnan BM (2002b) Phylogeography of western Pacific Leucetta 'chagosensis' (Porifera: Calcarea) from ribosomal DNA sequences: implications for population history and conservation of the Great Barrier Reef World Heritage Area (Australia). Mol Ecol 11: 1753-1768

Submitted: November 28, 2013; Accepted: November 6, 2014 Proofs received from author(s): February 13, 2015 